\title{
Migraine, tension-type headache, and depression among Saudi female students in Taif University
}

\author{
Dalia E. Desouky ${ }^{1,2^{*}}$, Hany A. Zaid ${ }^{1}$ and Azza A. Taha ${ }^{1,2}$
}

\begin{abstract}
Background: Studies done in Saudi Arabia showed a high prevalence of headache among university students. Limited research was done to assess the relationship between headache and psychiatric disorders. The aim of this study was to assess the prevalence and association between migraine, tension-type headache, and depression among Saudi female students in Taif University.

Participants and methods: A cross-sectional study using self-administered questionnaires about headache and depression was conducted at the Taif University on 1340 female students in the academic year 2016-2017. The Beck Depression Inventory, the ID Migraine ${ }^{T M}$ screening tool, and the criteria of the International Headache Society were used to investigate the depressive symptoms and headache types.

Results: The self-reported headache prevalence was $68.4 \%$, and the prevalence of migraine, tension-type headache $(\mathrm{TTH})$, and depression was 32.5\%, 29.5\%, and 6.2\%, respectively. The main migraine trigger was stress or anxiety; $86.6 \%$ of migraineurs had a positive family history, and only $11.9 \%$ sought medical care for headache. Of students with $T \mathrm{TH}$, $61.1 \%$ reported family history and only $12.4 \%$ sought medical care. Paracetamol was the commonly used analgesic for all headache types. Medical students and students in older grades showed significantly higher levels of all headache types. Depression prevalence was significantly higher among migraineurs and students who suffered higher headache frequencies.

Conclusion: The study demonstrated a high prevalence of headache among the studied students and an association between headache and depression. The study calls for increasing awareness towards headache and the importance of seeking medical consultation. Management strategies should be planned for the observed headache and depression comorbidity.
\end{abstract}

Keywords: Migraine, Headache, Depression, Saudi, Female, University

\section{Introduction}

Primary headache disorders including migraine and tension-type headache (TTH) are of great importance to global public health due to its high prevalence [1]. Migraine which is the main cause of headache worldwide is characterized by headache attacks that last between 4 and $72 \mathrm{~h}$ if untreated. It is one-sided pulsating or throbbing pain of moderate to severe intensity and associated with nausea or vomiting or both photophobia

\footnotetext{
* Correspondence: daliadesouky1234@gmail.com

${ }^{1}$ Department of Family and Community Medicine, College of Medicine, Taif University, Alsalama street, Taif city, Saudi Arabia

${ }^{2}$ Department of Public Health and Community Medicine, Faculty of Medicine, Menoufia University, Shibin El Kom, Egypt
}

and phonophobia [2]. Tension-type headache (TTH) is a headache where the pain is commonly described as "a band around the head". It has at least two of the following characteristics: mild to moderate in intensity, occurs on both sides of the head (bilateral), and not worsened by routine activity (bending over or climbing stairs), and pain has a pressing or tightening quality and not throbbing or pulsing. It is also not accompanied by nausea or vomiting [3].

Previous studies have shown a high prevalence of headache among university students [4-8]. Students' lifestyle puts them at high risk to suffer from fatigue, stress, and anxiety which are the most common causes 
of TTH and migraine [9]. Headache can make students suffer lost days of study, impaired academic performance, and poor quality of life [9]. The prevalence of migraine and TTH was reported to be higher among women $[4,10]$. This was explained by the effect of female hormone levels, particularly estrogen [11].

Migraine and TTH sufferers were found to have a higher risk to develop depression [12, 13]. Females suffer a higher prevalence of depression more than men, and they have an obvious disability due to harder pain attacks. That is why women suffer more headache and depression comorbidity [14]. On the other hand, psychiatric disorders as depression are associated with increased headache-related disability, frequency, severity and risk for chronicity. In addition, these disorders lower the overall quality of life among migraine and TTH sufferers [15].

In the Kingdom of Saudi Arabia (KSA), a country-wide population-based cross-sectional survey was done on 2421 adult population (18-65 years) in 2013 and found a $32 \%$ of 1 year prevalence of migraine headache [16]. Regarding the university students, a study on 400 female university students of King Saud University (2008) reported a prevalence of $25.7 \%$ of migraine [17]. A study done in King Faisal University (2013) on 100 female students showed a prevalence of $58.4 \%$ and $41.6 \%$ of migraine and TTH, respectively [7]. Another study was conducted on female medical students at Taibah University (2015) and found a history of headache in $92 \%$ of students and TTH prevalence of 58\% [18]. A recent study among female students at Taibah University (2016) demonstrated a prevalence of $61.8 \%$ of migraine among the participants [19].

A literature search of published studies showed that no study was done to assess the comorbidity of migraine, TTH, and depression among Saudi female university students. The aim of this study was to assess this comorbidity among female students at Taif University and the associated factors.

\section{Participants and methods}

\subsection{Study design and time frame}

A cross-sectional study was carried out on female students at Taif University in the period from February to June 2017.

\subsection{Sampling}

Multistage sampling methodology was carried out where Taif University was chosen. The university community of the female section of Taif University was the sampling frame. The university includes four medical colleges and seven non-medical colleges for females. The target population included all female students of the eleven colleges.

The total number of female students registered in the eleven colleges in the academic year 2016-2017 was
1733. A total coverage was done, and all students in the 11 colleges in all grades and classes were contacted. For each college, the Office of Student Affairs was contacted and a student list was obtained for every grade. With the help of the coordinator and the leader of every grade, questionnaire copies equal to the students' number in every grade were distributed by the researchers in the self-study session of students where they were free from any academic duty. After excluding non-respondents, and those who met the exclusion criteria (those with a past history of head or neck injury, nasal allergy or inflammation, headache of secondary neurological disorders, or systematic disease and pregnant students), the response rate was $77.3 \%$, and the total number of participants in the study was 1340 students.

The number of the eligible participants from each faculty was as follows: Faculty of Medicine (198 students), Faculty of Pharmacy (183), Faculty of Applied Medical Sciences (180), Faculty of Dentistry (157), Faculty of Science (85), Faculty of Literature (80), Faculty of Sharia and Law (96), Faculty of Education (86), Faculty of Design and Home Economics (94), Faculty of Computing and Information Technology (93), and Faculty of Managerial And Financial Sciences (88).

\subsection{Study instrument}

The study instrument was a pre-designed self-administered questionnaire that gathered information about age, college type, marital status, and educational grade. A stepwise approach was carried out to assess the prevalence of different types of headache, where a questionnaire to screen "headache" that contained three sections was used. The first section included a question to screen headache students, the second section included three questions to screen migraineurs, and the third section included four questions to screen students with TTH.

Step 1: For the determination of students with headache, an initial screening was carried out, where students who replied "yes" to this question: "Did you have two or more headaches in the last 3 months?" were the subjects with headache under consideration (916 students).

Step 2: For the screening of students who have migraine, students of positive answers in step 1 (916 students) were asked the three-item screening questions of the identification of migraine (ID Migraine ${ }^{\mathrm{m} m}$ screening tool): During the last 3 months, (1) Did you feel nauseated or sick in your stomach with your headaches? (2) Did light bother you when you had a headache (a lot more than when you do not have headaches)? and (3) Did your headache limit your ability to work, study, or do what you needed to do for at least 1 day? A test-diagnosis of migraine headache required at least two positive responses (436 students) [20]. 
The ID Migraine ${ }^{\mathrm{Tw}}$ is a widely used screening tool for migraine that has showed good validity for diagnosis of migraineurs at primary health care services, as it investigates the major aspects of migraine headache, which are nausea, photophobia, and disability [20]. This tool was developed and validated by Lipton et al. and can be applied quickly to large numbers of populations [21]. Sensitivity, specificity, and positive predictive value of this test in primary care were estimated to be $81 \%, 75 \%$, and $93 \%$, respectively [22]. This test was also validated to be applied to adolescent students with a sensitivity of $62.1 \%$ and specificity of $71.1 \%$ [20-22]. In addition, it was used in studies done on university students in Arab countries and in Saudi Arabia [10, 19, 23].

For measuring migraine severity, pain intensity was measured on a 4-point scale ranged from 0 to 3 , where 0 = no pain, 1 =mild, 2 = moderate, and $3=$ severe headache. This scale was recommended by the International Headache Society [22]. For assessing migraine triggers, a list of triggers was provided in the questionnaire and included stress or anxiety, irregular sleep, much reading, exams, smoking, menstruation, exposure to sun, and noise. The students were instructed about the possibility to give more than one answer.

Step 3: For the diagnosis of TTH, the criteria of the International Headache Society (IHS) was used, where students screened positive in step 1, and did not fulfill the headache criteria of step 2, were asked if headache is (1) of pressing (non-pulsating) quality, (2) of mild or moderate intensity (may inhibit but does not prohibit activities), (3) of bilateral location, and (4) not aggravated by climbing stairs or similar routine physical activity. Diagnosis of TTH required at least two positive answers to the previous four questions (396 students) [24].

In the second and third sections, questions on frequency of headache, family history, medical consultation for headache, medications used, frequency of analgesic use, increase in headache frequency after analgesic use, and increasing analgesic dose used over time were presented. For students who reported having headache but who did not fulfill any of the migraine or TTH criteria, they were classified as students with unknown headache (84 students).

To assess the prevalence of depression among students, Beck Depression Inventory (BDI) was used. It is a 21-item scale where each item was scored from 0 to 3 according to the symptom severity, with a total score ranging from 0 to 63. It was possible to give an answer with a score that ranged from 0 to 3 (absent, mild, moderate, and severe). The patient was diagnosed as normal if having a score less than 26, mild depression if the score ranged from 26 to 38 , moderate if ranged from 39 to 55 , and severe depression if ranged from 56 to 63 [25].

\subsection{Statistical analysis}

The data were coded, tabulated, and analyzed using the Statistical Package for the Social Sciences (SPSS, version 20; IBM Corp., Armonk, NY, USA). Qualitative data were expressed as numbers and percentages, and the chi-square $\left(\chi^{2}\right)$ test was used to test the relationship between variables. Quantitative data were expressed as mean and standard deviation (mean $\pm \mathrm{SD}$ ). A $p$ value of $<0.05$ was considered as statistically significant.

\section{Results}

Table 1 shows that the total number of the participants was 1340 female students, their mean age was $21.17 \pm 2.2$ years, $53.6 \%$ of them were from medical colleges and $89.9 \%$ were unmarried. Of the studied students, $68.4 \%$ reported having headache 2-3 times in the last 3 months, of them, $47.6 \%$ had migraine headache, $43.2 \%$ had TTH and $9.2 \%$ had

Table 1 Distribution of the studied female university students according to their personal characters, headache, and depression prevalence, Taif University, KSA, 2017

\begin{tabular}{|c|c|c|}
\hline \multirow[t]{2}{*}{ Variable } & \multicolumn{2}{|c|}{ Female university students $(n=1340)$} \\
\hline & No. & $\%$ \\
\hline \multicolumn{3}{|l|}{ College } \\
\hline - Medical & 718 & 53.6 \\
\hline - Non-medical & 622 & 46.4 \\
\hline Age (mean $\pm S D)$ & \multicolumn{2}{|c|}{$21.17 \pm 2.2($ range $=22-26)$} \\
\hline \multicolumn{3}{|l|}{ Marital status } \\
\hline - Married & 136 & 10.1 \\
\hline - Not married & 1204 & 89.9 \\
\hline \multicolumn{3}{|l|}{ Grade } \\
\hline - 1st grade & 286 & 21.3 \\
\hline - 2nd grade & 178 & 13.3 \\
\hline - 3rd grade & 220 & 16.4 \\
\hline - 4th grade & 178 & 13.3 \\
\hline - 5th grade & 222 & 16.6 \\
\hline - 6th grade & 256 & 19.1 \\
\hline \multicolumn{3}{|l|}{ Smoking } \\
\hline - Yes & 112 & 8.4 \\
\hline$-\mathrm{No}$ & 1228 & 91.6 \\
\hline \multicolumn{3}{|c|}{ Having headache $2-3$ times in the last 3 months } \\
\hline - No & 424 & 13.6 \\
\hline$-Y_{e s}^{ \pm}$ & 916 & 68.4 \\
\hline oMigraine & 436 & 32.5 \\
\hline оTTH & 396 & 29.5 \\
\hline oUnknown headache & 84 & 6.2 \\
\hline \multicolumn{3}{|l|}{ Depressive symptoms } \\
\hline - Present & 519 & 38.7 \\
\hline - Not present & 821 & 61.3 \\
\hline
\end{tabular}

${ }^{ \pm}$Percentages were calculated from the total sample 
Table 2 Distribution of migraineurs according to migraine characteristics, Taif University, KSA, 2017

\begin{tabular}{|c|c|c|}
\hline \multirow[t]{2}{*}{ Variable } & \multicolumn{2}{|c|}{ Migraineur students $(n=436)$} \\
\hline & No. & $\%$ \\
\hline \multicolumn{3}{|c|}{ Headache limit the ability to study or enjoy life } \\
\hline - Yes & 371 & 85.1 \\
\hline - No & 65 & 14.9 \\
\hline \multicolumn{3}{|l|}{ Severity of migraine attacks } \\
\hline - Mild & 23 & 5.3 \\
\hline - Moderate & 218 & 50.0 \\
\hline - Sever & 195 & 44.7 \\
\hline \multicolumn{3}{|l|}{ Migraine triggers ${ }^{\#}$} \\
\hline - Stress or anxiety & 225 & 51.6 \\
\hline - More than one answer & 80 & 18.3 \\
\hline - Irregular sleep & 48 & 11.0 \\
\hline - Menstruation & 35 & 8.0 \\
\hline - Smoking & 18 & 4.1 \\
\hline - Much reading & 16 & 3.7 \\
\hline - Noise & 10 & 2.3 \\
\hline - Exams & 2 & 0.5 \\
\hline - Exposure to sun & 2 & 0.5 \\
\hline \multicolumn{3}{|l|}{ Frequency of migraine per month ${ }^{\#}$} \\
\hline - Daily & 53 & 12.2 \\
\hline - Fewer than daily to weekly & 190 & 43.6 \\
\hline - Fewer than weekly to monthly & 169 & 38.8 \\
\hline - Fewer than monthly to 1 year & 24 & 5.5 \\
\hline \multicolumn{3}{|l|}{ Family history of migraine } \\
\hline - Yes & 200 & 45.9 \\
\hline - No & 236 & 54.1 \\
\hline \multicolumn{3}{|l|}{ Seeking medical care for migraine } \\
\hline - Yes & 52 & 11.9 \\
\hline - No & 384 & 88.1 \\
\hline \multicolumn{3}{|l|}{ Advice to taker analgesic was by } \\
\hline - Physician & 61 & 14 \\
\hline - Pharmacist & 33 & 7.6 \\
\hline - Family members & 300 & 68.8 \\
\hline - Others: friends, colleagues, neighbors & 42 & 9.6 \\
\hline \multicolumn{3}{|l|}{ Frequency of analgesic use } \\
\hline - Daily & 18 & 4.1 \\
\hline - Fewer than daily to weekly & 409 & 93.8 \\
\hline - Fewer than weekly to monthly & 7 & 1.6 \\
\hline - Fewer than monthly to 1 year & 2 & 0.5 \\
\hline \multicolumn{3}{|c|}{ Increase in headache frequency after analgesic use } \\
\hline - Yes & 38 & 8.7 \\
\hline- No & 398 & 91.3 \\
\hline
\end{tabular}

Increase analgesic dose used over time
Table 2 Distribution of migraineurs according to migraine characteristics, Taif University, KSA, 2017 (Continued)

\begin{tabular}{lll}
\hline Variable & \multicolumn{2}{l}{ Migraineur students $(n=436)$} \\
\cline { 2 - 3 } & No. & $\%$ \\
\hline - Yes & 318 & 72.9 \\
- No & 118 & 27.1 \\
Type of analgesic used ${ }^{\#}$ & & \\
- Paracetamol & 235 & 53.9 \\
- Ibuprofen & 141 & 32.3 \\
- Acetaminophen & 52 & 11.9 \\
- Aspirin & 6 & 1.4 \\
- Diclofenac sodium & 2 & 0.5 \\
\hline
\end{tabular}

"Multiple responses

unknown headache. No one was classified to have both migraine and TTH. Depression prevalence among studied students was $38.7 \%$.

In Table 2, 85.1\% of migraineur students stated that headache limited their ability to study or enjoy life, and 94.7\% reported that their headache was of moderate to severe intensity. The main trigger for migraine attacks was stress or anxiety, and $18.3 \%$ of migraineurs reported the presence of more than one trigger. Most of the migraineurs (43.6\%) reported that the frequency of migraine attacks per month was fewer than daily to weekly, and $86.6 \%$ reported a family history of migraine.

Only $11.9 \%$ of the migraineurs sought medical care, $68.8 \%$ took analgesic according to an advice from a family member, and only $21.6 \%$ of them took analgesic according to an advice from a physician or a pharmacist. In the vast majority of migraineurs (93.8\%), the frequency of analgesic use was fewer than daily to weekly, with $72.9 \%$ of them reported an increase in the analgesic dose used over time. The main analgesic used was paracetamol (53.9\%), followed by ibuprofen, acetaminophen, aspirin, and diclofenac sodium $(32.3 \%, 11.9 \%, 1.4 \%$, and $0.5 \%$, respectively).

Table 3 shows that only $4.5 \%$ of students with TTH reported that headache affected their daily activities, $61.1 \%$ reported a family history of $\mathrm{TTH}$, and the majority (71.7\%) stated that the frequency of headache attacks per month was fewer than weekly to monthly. Only $12.4 \%$ of TTH students sought medical care, and $69.4 \%$ took analgesic according to an advice from a family member. The frequency of analgesic use was fewer than weekly to monthly in about half of the students. The majority of TTH students reported no increase in headache frequency after analgesic use or increase in the analgesic dose used over time. The main analgesic used was paracetamol $(46.5 \%)$, followed by ibuprofen, acetaminophen, aspirin, and diclofenac sodium (33.8\%, $13.9 \%, 3 \%$, and $2.8 \%$, respectively). 
Table 3 Distribution of participants with TTH according to tension headache characteristics, Taif University, KSA, 2017

\begin{tabular}{|c|c|c|}
\hline \multirow[t]{2}{*}{ Variable } & \multicolumn{2}{|c|}{ Students with TTH $(n=396)$} \\
\hline & No. & $\%$ \\
\hline \multicolumn{3}{|l|}{ Headache affecting daily activities } \\
\hline - Yes & 18 & 4.5 \\
\hline$-\mathrm{No}$ & 378 & 95.5 \\
\hline \multicolumn{3}{|l|}{ Family history of TTH } \\
\hline - Yes & 172 & 43.4 \\
\hline$-\mathrm{No}$ & 224 & 56.6 \\
\hline \multicolumn{3}{|l|}{ Frequency of TTH per month } \\
\hline - Daily & 12 & 3.0 \\
\hline - Fewer than daily to weekly & 30 & 7.6 \\
\hline - Fewer than weekly to monthly & 284 & 71.7 \\
\hline - Fewer than monthly to 1 year & 70 & 17.7 \\
\hline \multicolumn{3}{|l|}{ Seeking medical care for $\mathrm{TH} H$} \\
\hline - Yes & 49 & 12.4 \\
\hline$-\mathrm{No}$ & 347 & 87.6 \\
\hline \multicolumn{3}{|l|}{ Advice to taker analgesic was by } \\
\hline - Physician & 34 & 8.6 \\
\hline - Pharmacist & 30 & 7.6 \\
\hline - Family members & 275 & 69.4 \\
\hline - Others: friends, colleagues, neighbors & 57 & 14.4 \\
\hline \multicolumn{3}{|l|}{ Frequency of analgesic use } \\
\hline - Daily & 12 & 3.0 \\
\hline - Fewer than daily to weekly & 154 & 38.9 \\
\hline - Fewer than weekly to monthly & 192 & 48.5 \\
\hline - Fewer than monthly to 1 year & 38 & 9.6 \\
\hline \multicolumn{3}{|c|}{ Increase in headache frequency after analgesic use } \\
\hline - Yes & 96 & 24.2 \\
\hline$-\mathrm{No}$ & 300 & 75.8 \\
\hline \multicolumn{3}{|l|}{ Increase analgesic dose used over time } \\
\hline - Yes & 41 & 10.4 \\
\hline$-\mathrm{No}$ & 355 & 89.6 \\
\hline \multicolumn{3}{|l|}{ Type of analgesic used } \\
\hline - Paracetamol & 184 & 46.5 \\
\hline - Ibuprofen & 134 & 33.8 \\
\hline - Acetaminophen & 55 & 13.9 \\
\hline - Aspirin & 12 & 3.0 \\
\hline - Diclofenac sodium & 11 & 2.8 \\
\hline
\end{tabular}

Figure 1 shows that a significant difference was found between medical and non-medical students according to the prevalence of different types of headache, with medical students showing significantly higher levels of all types of headache $\left(\chi^{2}=8.071\right.$ and $\left.p=0.018\right)$. According to the students' grades, the first and older grades showed a significantly higher prevalence of both migraine and TTH $\left(\chi^{2}=76.59\right.$ and $\left.p \leq 0.001\right)$.

Figure 2 shows that the depression prevalence was significantly higher among migraineur students compared to students with TTH and unknown headache $(51.8 \%$ vs $43.4 \%$ and $34.5 \%)\left(\chi^{2}=11.1\right.$ and $\left.p=0.003\right)$. Depression prevalence was also significantly higher among students who suffered higher headache frequencies $\left(\chi^{2}=26.6\right.$ and $p \leq 0.001)$.

\section{Discussion}

In the present study, $68.4 \%$ of students had a headache two to three times in the last 3 months. This result is somewhat in agreement with the results revealed from a study done on university students of both sexes in India (63.9\%) [4] and Ethiopia (67.22\%) [5]. A nearby prevalence was also revealed from a study done on female students of King Faisal University in KSA, where the prevalence of headache was 77\% [7].

Lower headache prevalence was reported from other studies done on university students in Iran (58.7\%) [26] and South Africa (50.2\%) [27]. These lower rates could be attributed to the diagnosis of headache by a questionnaire followed by a physical examination, while in the present study, diagnosis was based only on the self-administered questionnaire without physical examination.

In the same time, higher headache prevalence was reported from other studies done on university students in Brazil (74.5\%) [6] and in Iran (90.5\% in males and $88.8 \%$ in females) [8]. According to studies done on university students in KSA, higher headache prevalence (92\%) was reported from a study done on female university students at Taibah University (2015) [19].

This high prevalence observed in the previous studies could be explained by conducting these studies only on medical students. According to Deleu et al., medical students commonly suffer from emotional stress, poor sleeping, and eating behaviors than the general population because of their academic life, which are common triggers for headache [28].

The prevalence of TTH reported in the present study (29.5\%) lies within the range reported from populationbased studies which ranged from 12 to 78\% [29]. Higher prevalence was reported from a previous Saudi study done on female university students from different colleges where $41.6 \%$ of students had TTH [7]. A higher prevalence (58\%) was also reported in another Saudi study done at Taibah University, which could be explained by conducting that study on medical students [18].

For migraine prevalence, a higher prevalence was reported in previous Saudi studies done on university students of King Faisal University (58.4\%) [7] and Taibah University (61.8\%) [19]. The lower prevalence found in our study $(32.5 \%)$ could be explained by the fact 


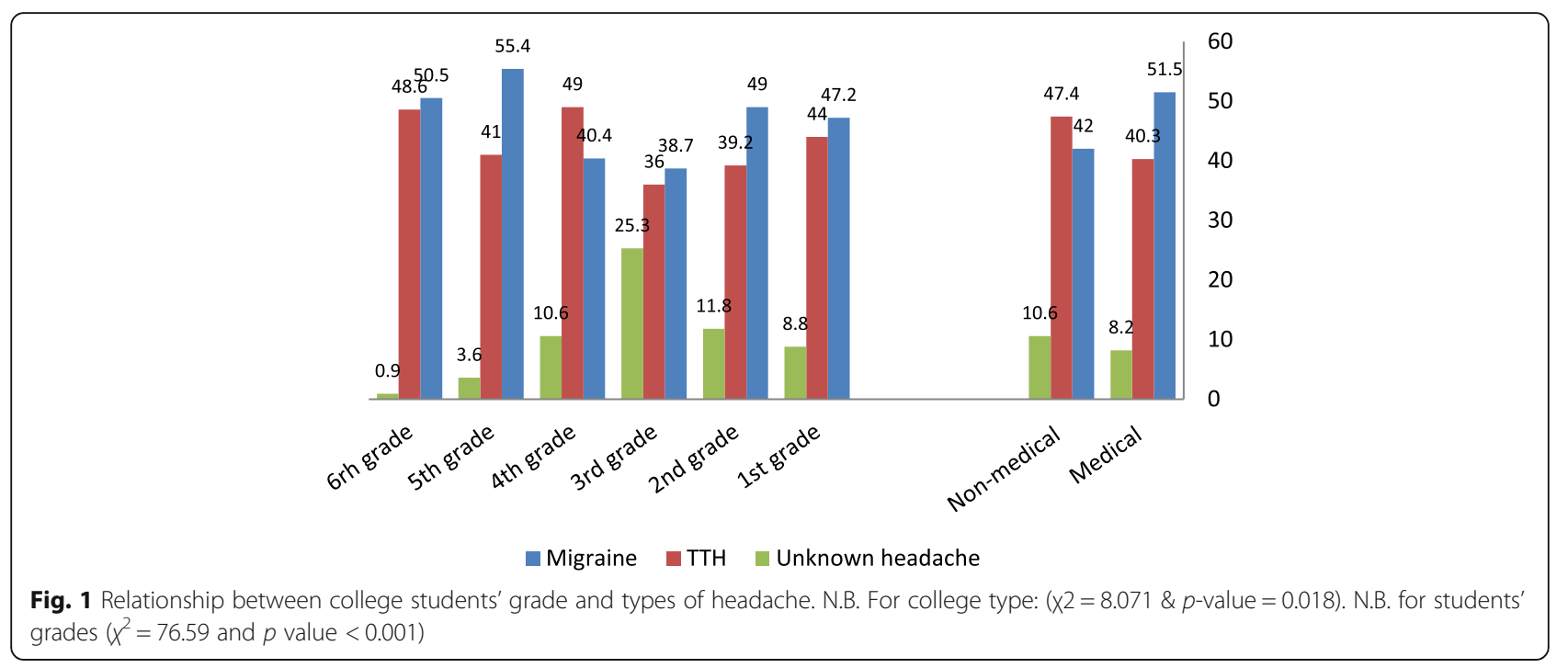

that we only describe a 3-month prevalence. In the same time, lower migraine prevalence was reported from other studies done on university students in other Arab and foreign countries [10, 21], and in a study done in KSA [17].

The variation between our results and others in the prevalence of both migraine and TTH could be explained by the difference in the population studied as our participants were only females. The difference in the methodology used and the sampling criteria and the diagnostic parameters used could also be considered for this variability [30]. In addition, genetic characteristic; environmental, cultural, racial, and climate aspects; triggering factors; and different socioeconomic or nutritional status could explain this variation across countries [31].

In the present study, the main trigger for migraine attacks was stress or anxiety, and $18.3 \%$ of migraineurs reported the presence of more than one trigger. This result is going with those revealed from other national and international studies $[9,24,32]$.

In the present work, $86.6 \%$ of migraineur students and $61.1 \%$ of students with TTH reported having a family history, a finding consistently found in previous studies and may highlight the role of genetics in this concern [5, 33, 34].

Seeking medical consultation for headache management was poor; only $11.9 \%$ of migraineur students and

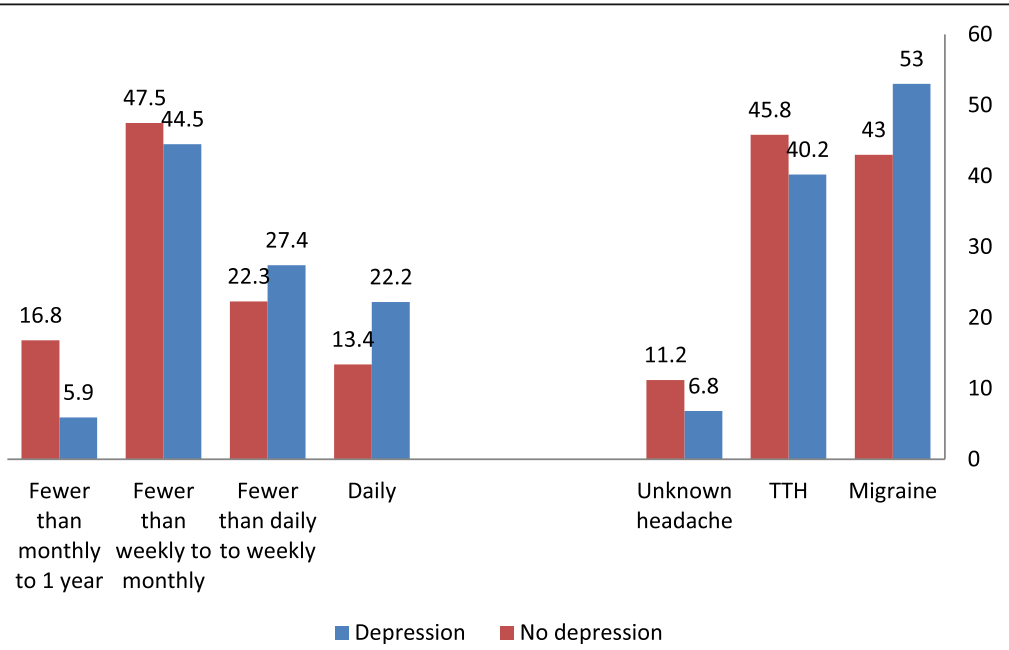

Fig. 2 Relationship between depression, headache types, and headache frequency. N.B. for headache types $\left(x^{2}=11.1\right.$ and $p$ value $\left.=0.003\right)$. N.B. for headache frequency $\left(x^{2}=26.6\right.$ and $p$ value $\left.<0.001\right)$ 
$12.4 \%$ of students with TTH reported seeking medical care. This very low figure was reported in previous studies done in Jordan [33] and Yemen [34]. Low level of headache consultation was also reported in other international studies, which showed that a small percentage of younger generation visit health professionals for their headache [35].

In the present study, the majority of migraineurs and students with TTH took analgesic according to an advice from a family member, and about one fifth of them took analgesic according to an advice from a physician or a pharmacist. Similar results were reported in previous studies done in Arab countries [33].

For the majority of both migraineurs and TTH students, paracetamol was the commonly used analgesic followed by ibuprofen and acetaminophen, a finding which is in agreement with those revealed from various studies [4-6]. The popularity of paracetamol and acetaminophen was explained in the previous studies by their low price, safety, and less GIT side effects, in addition to their availability as an over-the-counter medication [28, 34].

Medical students in the present study showed significantly higher levels of migraine headache. This result is in line with those revealed from previous national and international studies done on medical students $[4,8,9,19]$. This significant difference was explained by emotional stress, anxiety, poor lifestyle, and other risk factors that trigger headache among medical students. Of these, the risk factors are the high level of stress they face due to exams, high-level performance, and many years of learning and training [11].

The prevalence varies also by grade level, where the first and older grades (fifth and sixth) showed a significantly higher prevalence of both migraine and TTH. This result could be explained in the light of having $53.6 \%$ of the participants from medical colleges. The present result is in agreement with a Kuwaiti study, where the last two grades had a higher prevalence of migraine headache which was explained by the increasing frequency of exams in the last academic years with a subsequent increase of stress and reading hours and can lead to irregular sleeping pattern [11].

A result was observed in a national study done on medical students of King Saud Bin Abdulaziz University, where the last grades showed a higher prevalence of migraine headache. The study explained this result in the light of exposure of students to emotional stress as they start their internship in different hospitals and cities which is a hard and critical time for students as they have to integrate both internship working and studying for the Saudi Medical License Exam (SMLE) [25]. The high prevalence of headache among the first grade was revealed from other studies which was explained by the emotional stresses faced by those students in their first academic year [11].

In the present study, the prevalence of depression among the studied sample was $38.7 \%$. This result is lower than that revealed from previous Saudi studies done on university students, a matter that could be explained by conducting those studies on exclusively medical students who face lots of stressors $[19,35]$. On the other hand, lower prevalence of depression was reported in another Saudi study done at King Faisal University, where the prevalence was $24.4 \%$ [36]. This could be attributed to conducting the present work on female students only, where females were found to have a higher prevalence of psychiatric disorders due to the hormonal and serotonin effects [37]. In addition, the Saudi Community imposes more restrictions on girls' more than boys' behaviors and has lower expectations for girls' than for boys' competencies and achievements [38].

Depression prevalence was significantly higher among migraineur students. This result is in line with that observed in other studies which showed that $62.5 \%$ of migraineurs had at least one psychiatric comorbidity [14, 16]. Depression prevalence was significantly higher among students who suffered higher headache frequencies, a result that was observed in previous studies, where higher scores of depressive symptoms were associated with recurrent headache attacks $[13,39]$.

\subsection{Limitations}

One of the limitations of this study was using self-reported questionnaires for collecting data which were prone to recall bias. Another limitation was being a cross-sectional study which showed the relation between variables without concluding a cause-effect relationship. Longitudinal studies should be encouraged to determine the causality among variables. In addition, medical students contributed to a relatively large number of the sample. This was the result of the higher response rate from medical colleges as their counterparts from non-medical colleges were engaged in the midterm exam at the time of data collection.

\section{Conclusion and recommendations}

This study demonstrated a high prevalence of headache among studied students and an association between headache and depression. The study calls for increasing awareness towards headache and the importance of seeking medical consultation. Management strategies should be planned, and interventions should be implemented to deal with the problem of headache and depression comorbidity.

\section{Acknowledgements}

The authors gratefully acknowledge the support provided by the officials of the studied colleges for facilitating the administrative aspects of this

research. Participant students deserve special thanks for their cooperation. 


\section{Funding}

None

\section{Availability of data and materials}

Data sharing not applicable to this article as no datasets were generated or analyzed during the current study. Please contact the authors for data requests.

\section{Authors' contributions}

Dr. DD designed the study, developed the questionnaire and the informed consent, wrote the protocol, and planned the study. She assisted in the data collection and data entry and did the statistical design and analysis. She will take the primary responsibility in responding to the reviewers' comments. Dr. HAZ participated in the study planning, took the responsibility of the administrative aspects of the research, and assisted in the data entry. Dr. AAT helped in study planning, questionnaire development, data collection and data entry. All authors read and approved the final manuscript.

\section{Ethics approval and consent to participate}

Official approvals were obtained from the Research Ethics Committee of Taif University and from the deanships of the colleges included in the study. As long as the study does not take samples from humans, there is no probability of a potential harm and all students were more than 18 years, the ethics committee approved obtaining verbal consents from the respondent students before sharing in the study

\section{Consent for publication}

The manuscript does not contain any individual person's data in any form (individual details, images or videos).

\section{Competing interests}

The authors declare that they have no competing interests.

\section{Publisher's Note}

Springer Nature remains neutral with regard to jurisdictional claims in published maps and institutional affiliations.

Received: 30 October 2018 Accepted: 10 January 2019 Published online: 29 January 2019

\section{References}

1. Global Burden of Disease Study 2013 Collaborators. Global, regional, and national incidence, prevalence, and years lived with disability for 301 acute and chronic diseases and injuries in 188 countries, 1990-2013: a systematic analysis for the global burden of disease study 2013. Lancet. 2015;386:743-800.

2. Lipton RB, Pavlovic JM, Haut SR, Grosberg BM, Buse DC. Methodological issues in studying trigger factors and premonitory features of migraine. Headache. 2014;54(10):1661-9.

3. American migraine foundation. Tension type headache: the basics. [Accessed 2017 March 15]. Available from: https:// americanmigrainefoundation.org/resource-library/tension-type-headache/.

4. Nandha R, Chhabra MK. Prevalence and clinical characteristics of headache in dental students of a tertiary care teaching dental hospital in Northern India. Int J Basic Clin Pharmacol. 2013;2(1):51-5.

5. Birru EM, Abay Z, Abdelwuhab M, Basazn A, Betelhem Sirak B, Teni FS. Management of headache and associated factors among undergraduate medicine and health science students of University of Gondar, North West Ethiopia. J Headache Pain. 2016;17:56-65.

6. Falavigna A, Teles AR, Velho MC, Vedana VM, Castilhos da Silva $R$, Mazzocchin T, et al. Prevalence and impact of headache in undergraduate students in Southern Brazil. Arq Neuropsiquiatr. 2010;68(6):873-7.

7. Al-Hassanl ES, Al-Mulifi AA, Al-Khudhayr AM, Al-Quraini AW, Al-Omran AM, Al-Musallam EJ, et al. Prevalence of headache in female students in King Faisal University: a questionnaire study. Int J Sci Res. 2013;5(6):256-60.

8. Shahrakai MR, Mirshekari H, Ghanbari AT, Shahraki AR, Shahraki E. Prevalence of migraine among medical students in Zahedan faculty of medicine (southeast of Iran). Basic Clin Neurosci. 2011;2(2):20-5.

9. Souza-e-Silva HR, Rocha-Filho PA. Headaches and academic performance in university students: a cross-sectional study. Headache. 2011;51:1493-502.

10. Al-Hashel JY, Ahmed SF, Alroughani R, Goadsby PJ. Migraine among medical students in Kuwait University. J Headache Pain. 2014;15:26-32.
11. Chu MK, Kim DW, Kim BK, Kim JM, Jang TW, Park JW, et al. Gender-specific influence of socioeconomic status on the prevalence of migraine and tension-type headache: the results from the Korean headache survey. J Headache Pain. 2013;14:82-8.

12. Falavignaa A, Teles AR, Bragac GL, Conzattic LP, Ruschelc LG, Guarise da Silvac $P$. Association between primary headaches and depression in young adults in southern Brazil. Rev Assoc Med Bras. 2013;59(6):589-93.

13. Bera SC, Khandelwal SK, Sood M, Goyal V. A comparative study of psychiatric comorbidity, quality of life and disability in patients with migraine and tension type headache. Neurol India. 2014;62(5):516-20.

14. Ligthart L, Gerrits MM, Boomsma DI, Penninx BW. Anxiety and depression are associated with migraine and pain in general: an investigation of the interrelationships. J Pain. 2013;14(4):363-70.

15. Buse DC, Loder EW, Gorman JA, Stewart WF, Reed ML, Fanning KM, et al. Sex differences in the prevalence, symptoms, and associated features of migraine, probable migraine and other severe headache: results of the American Migraine Prevalence and Prevention (AMPP) study. Headache. 2013;53(8):1278-99.

16. Al Jumah MA, Hussein M, Al Khathaami A, Kojan S, Stovner L, Steiner T. The prevalence of primary headache disorders in Saudi Arabia. Neurol Sci. 2013; 333 Suppl 1:e499.

17. Tayel SS. Effect of migraine headache on academic performance and quality of life of female students at King Saud University, Kingdom of Saudi Arabia. Bull Alex Fac Med. 2008;44(2):503-9.

18. Al-Jabry NT, Abduljabbar Z, Maqsud AN, Alhadad BA, Almukhtar NM, AlMutairy SA, et al. Prevalence and risk factors of tension headache among 3rd year female medical students at Taibah University in Saudi Arabia. Int J Academic \& Sci Res. 2015;3(4):46-53.

19. Garah M, Neyaz H, Shaqrun F, Alhussaini K, Hafiz B, Alrehaili M, et al. Prevalence of migraine among female students at Ttaibah University, Kingdom of Saudi Arabia. Int J Adv Res. 2016;4(7):1526-34.

20. Lipton RB, Dodick D, Sadovsky R, Kolodner K, Endicott J, Hettiarachchi J, et al. A self-administered screener for migraine in primary care: the ID Migraine(TM) validation study. Neurology. 2003;61:375-82.

21. Lipton R, Liberman J, Kolodner K, Bigal M, Dowson A, Stewart W. Migraine headache disability and health-related quality-of-life: a population based case-control study from England. Cephalalgia. 2003;23(6):441-50.

22. Tfelt-Hansen P, Pascual J, Ramadan N, Dahlof C, D'Amico D, Diener HC, et al. international headache society clinical trials subcommittee. Guidelines for controlled trials of drugs in migraine: third edition. A guide for investigators. Cephalalgia 2012; 32:6-38.

23. Alwahbi MK, Alamri MM, Alammar AM, Alanazi AM, Abdulaziz G, Alotaibi AG, et al. Prevalence of migraine among medical students of King Saud bin Abdulaziz University for Health Sciences. Int J Sci Res (IJSR). 2017;6(2):894-8.

24. Headache Classification Subcommittee of the International Headache Society. The international classification of headache disorders. Cephalalgia. 2004;24 Suppl 1:9-160.

25. Ghareeb AG. Manual of Arabic BDI-II. Alongo Press. Cairo inventory: the author's twenty-five years of evaluation. Clin Psychol Rev. 2000;8:77-100.

26. Ghorbani A, Abtahi SM, Fereidan-Esfahani M, Abtahi SH, Shemshaki H, Akbari $\mathrm{M}$, et al. Prevalence and clinical characteristics of headache among medical students, Isfahan, Iran. J Res Med Sci. 2013;18(Suppl 1):S24-S7.

27. Basdav J. The prevalence and impact of primary headaches on students at the Durban based campuses of the Durban University of Technology (DUT). Minidissertation submitted in partial compliance with the requirements of the master's degree in technology: chiropractic in the Faculty of Health Sciences Durban University of Technology Durban. 2016. [Accessed 5 Feb 2017]. Available from: https://ir.dut.ac.za/bitstream/10321/1510/1/BASDAV_2016.pdf.

28. Deleu D, Khan M, Humaidan H, Al Mantheri Z, Hashamis A. Prevalence and clinical characteristics of headache in medical students in Oman. Headache. 2001;41(8):798-04

29. Stovner LJ, Hagen K, Jensen R, Katsarava Z, Lipton R, Scher A. The global burden of headache: a documentation of headache prevalence and disability worldwide. Cephalalgia. 2007;27(3):193-210.

30. Steiner TJ, Stovner $\sqcup$, Al Jumah M, Birbeck GL, Guruaj G, Jensen R, et al. Improving quality in population surveys of headache prevalence, burden and cost: key methodological considerations. J Headache Pain. 2013;14(1):87-97.

31. Victor T, Hu X, Campbell J, Buse D, Lipton R. Migraine prevalence by age and sex in the United States: a life-span study. Cephalalgia. 2010;30(9):1065-72.

32. Galinović I, Vuković V, Troselj M, Antić S, Demarin V. Migraine and tension type headache in medical students: a questionnaire study. Coll Antropol. 2009;33(1):169-73. 
33. Alzoubi KH, Mhaidat N, Al Azzam S, Khader Y, Salem S, Issaifan H, et al. Prevalence of migraine and tension-type headache among adults in Jordan. $J$ Headache Pain. 2009;10:265-70.

34. Abdo SA, AL-Kamarany MA, Alzoubi KH, Al-Maktari MT, Al-Baidani AH. Primary headache in Yemen: prevalence and common medications used. Neurol Res Int. 2014;2014:1-6.

35. Inam SNB. Anxiety and depression among students of a medical college in Saudi Arabia. Int J Health Sci (Qassim). 2007;1(2):295-300.

36. Amr M, Amin TT, Saddichha S, Al Malki S, Al Samail M, Al Qahtani N, et al. Depression and anxiety among Saudi University students: prevalence and correlates. The Arab J Psychiatry. 2013;24(1):1-7.

37. Baskin SM, Smitherman TA. Migraine and psychiatric disorders: comorbidities, mechanisms, and clinical applications. Neurol Sci. 2009;30:61-5.

38. Nolen-Hoeksema S. Gender differences in depression. Department of Psychology, University of Michigan, Ann Arbor, Michigan, American Psychological Society 2001. [Accessed 10 Feb 2017]. Available from: https:// journals.sagepub.com/doi/pdf/10.1111/1467-8721.00142.

39. Palacios-Ceña MJ, Fernández-Muñoz J, Castaldo M, Wang K, Guerrero-Peral A, Arendt-Nielsen $L$, et al. The association of headache frequency with pain interference and the burden of disease is mediated by depression and sleep quality, but not anxiety, in chronic tension type headache. J Headache Pain. 2017:18:19-27.

\section{Submit your manuscript to a SpringerOpen ${ }^{\circ}$ journal and benefit from:}

- Convenient online submission

- Rigorous peer review

- Open access: articles freely available online

High visibility within the field

- Retaining the copyright to your article

Submit your next manuscript at $\boldsymbol{\nabla}$ springeropen.com 